\title{
Right ventricular failure secondary to chronic overload in congenital heart diseases: Benefits of cell therapy using human embryonic stem cell-derived cardiac progenitors
}

\author{
Virginie Lambert, MD, $\mathrm{PhD},{ }^{\mathrm{a}, \mathrm{b}, \mathrm{c}}$ Elodie Gouadon, $\mathrm{PhD},{ }^{\mathrm{a}, \mathrm{b}}$ André Capderou, $\mathrm{MD}, \mathrm{PhD},{ }^{\mathrm{a}, \mathrm{b}}$ \\ Emmanuel Le Bret, MD, PhD, ${ }^{\mathrm{c}}$ Mohamed Ly, MD, ${ }^{\mathrm{c}}$ Sylvie Dinanian, MD, ${ }^{\mathrm{d}}$ \\ Jean-Francois Renaud, $\mathrm{PhD},{ }^{\mathrm{a}, \mathrm{b}}$ Michel Pucéat, $\mathrm{PhD},{ }^{\mathrm{e}}$ and Catherine Rücker-Martin, $\mathrm{PhD}^{\mathrm{a}, \mathrm{b}}$
}

\begin{abstract}
Objective: Despite the increasing incidence of right ventricular (RV) failure in adult patients with congenital heart disease, current therapeutic options are still limited. By contrast to left-heart diseases, cell-based myocardial regeneration applied to the right ventricle is poorly studied, even though it may be a therapeutic solution. As human embryonic stem cell-derived cardiac progenitors seem to be good candidates owing to their proliferation capacity, our aim was to assess, in a large animal model of overloaded RV dysfunction, the feasibility and effects of such a cell therapy.
\end{abstract}

Methods: Human $\mathrm{MesP}^{+} / \mathrm{SSEA}-1^{+}$cardiogenic mesodermal cells were administered using multiple intramyocardial injections 4 months after a surgical procedure mimicking the repaired tetralogy of Fallot, and their effects were observed 3 months later on hemodynamic, rhythmic, and histologic parameters.

Results: All pigs ( $\operatorname{sham} n=6$, treated $n=6$ ) survived without complication, and cell therapy was clinically well tolerated. Although functional, contractility, and energetics parameters evolved similarly in both groups, benefits regarding arrhythmic susceptibility were observed in the treated group, associated with a significant decrease of peri-myocyte fibrosis $(5.71 \% \pm 2.49 \%$ vs $12.12 \% \pm 1.85 \% ; P<.01)$ without interstitial fibrosis change $(5.18 \% \pm 0.81 \%$ vs $5.49 \% \pm 1.01 \%)$. Such a decrease could be related to paracrine effects, as no human cells could be detected within the myocardium.

Conclusions: Cell therapy using intramyocardial injections of human $\mathrm{MesP} 1^{+} / \mathrm{SSEA}-1^{+}$cardiogenic mesodermal cells seems to have benefits regarding overloaded RV tissue remodeling and arrhythmic susceptibility, but this mode of administration is not sufficient to obtain a significant improvement in RV function. (J Thorac Cardiovasc Surg 2015;149:708-15)

See related commentary on pages 715-7.

Supplemental material is available online.

From the Medical Research Department, ${ }^{\text {a }}$ Centre Chirurgical Marie Lannelongue, Inserm UMR_S999, LabEx LERMIT, Le Plessis-Robinson; Université Paris Sud, ${ }^{\text {b }}$ DHU Thorax Innovation, Le Kremlin-Bicêtre; Department of Pediatric and Congenital Heart Diseases, ${ }^{c}$ Centre Chirurgical Marie Lannelongue, Le Plessis-Robinson; Département de Cardiologie, ${ }^{\mathrm{d}}$ Centre Hospitalier Antoine Béclère, Clamart; and Inserm UMR_S910, ${ }^{\mathrm{e}}$ Faculté de Médecine de la Timone, Marseille, France.

Supported by the Association Française contre les Myopathies, grants numbers 12063, 13056, and 13968, Evry, France; the Agence Nationale pour la Recherche, grant number ANR-06-MRAR-041-03 Cardiostem, Paris, France; and Field of Major Interest STEM Pole 2008-2010, IDF Paris, France.

Disclosures: Authors have nothing to disclose with regard to commercial support.

Received for publication June 27, 2014; revisions received Oct 7, 2014; accepted for publication Nov 16, 2014; available ahead of print Jan 10, 2015.

Address for reprints: Virginie Lambert, MD, PhD, Centre Chirurgical Marie Lannelongue, 133 Ave de la Résistance, 92350 Le Plessis-Robinson, France (E-mail: v.lambert@ccml.fr).

$0022-5223 / \$ 36.00$

Copyright (c) 2015 by The American Association for Thoracic Surgery

http://dx.doi.org/10.1016/j.jtcvs.2014.11.033
Right ventricular (RV) failure remains a major problem in the long-term follow-up of patients with congenital heart disease, leading to impairment of functional status, severe arrhythmias, and premature death. ${ }^{1}$ This RV dysfunction occurs in young adults as a consequence of chronic pressure and volume overload secondary to procedures that had early success, in patients with either 2 ventricles in which the right ventricle was abnormal (eg, tetralogy of Fallot [TOF]), or was the dominant or systemic ventricle (eg, hypoplastic left heart syndrome). ${ }^{2}$ In these patients, more than $50 \%$ have a risk of heart failure after age 30 years ${ }^{1}$ Moreover, RV function is a major prognostic factor of pulmonary artery hypertension, regardless of etiology. ${ }^{3}$ Consequently, management of RV failure was identified as a priority in cardiology research. ${ }^{4}$

By contrast to left ventricular failure, clinical management of patients with RV failure remains challenging: drugs or resynchronization give variable benefits, ${ }^{5}$ and surgical procedures such as valve replacement or repair may delay RV failure, but may fail to improve altered RV function. At the end-stage of heart failure, cardiac transplantation is mandated, but its application is restricted by the availability 


\author{
Abbreviations and Acronyms \\ DNA $=$ desoxuribose nucleic acid \\ $\mathrm{ECG}=$ electrocardiogram \\ $\mathrm{ESC}=$ embryonic stem cell \\ HD = high-density \\ PVS $=$ programmed ventricular stimulation \\ $\mathrm{RV}=$ right ventricular \\ TOF $=$ tetralogy of Fallot
}

of donor organs. Cell-based myocardial repair may be an alternative approach. Human embryonic stem cell (ESC) engraftments were successfully attempted in left ventricular myocardium after ischemic injuries. ${ }^{6}$ Regarding the right ventricle, cell therapy using myoblastic ${ }^{7}$ or cord-blood stem cells ${ }^{8,9}$ has been attempted but yielded poor results.

Treating RV failure, in contrast to ischemic left ventricle, by cell therapy, has to take into account not only the postoperative scarred area, but also the specific geometry and physiologic processes of the right ventricle. Indeed, RV chronic overload alters the entire RV myocardium. ${ }^{10,11}$ This extensive alteration requires a substantial number of cells to treat, and potentially induce a functional improvement of, the RV myocardium. Among multiple cell types considered as potential sources of cardiac progenitors, some did establish a functional coupling with the host myocardium. ${ }^{6,12,13}$ ESCs derived from the inner mass of the blastocyst possess this capacity and are able to proliferate, differentiate in vivo into mature cardiac myocytes, and repopulate significant regions of the damaged myocardium.

A proof of concept has been reported in a nonhumanprimate model of infarcted myocardium. ${ }^{6,13}$ In one of these models, ${ }^{13}$ the maturation and differentiation of cardiac progenitors into ventricular myocytes seemed to be optimal in areas composed of both fibrosis and damaged cardiac fibers. Instances in which such a structural remodeling constitutes a favorable environment for stem-cell grafting has been observed in patients with overloaded RV dysfunction, ${ }^{14}$ suggesting that cardiac progenitor cell therapy may be applied in this indication.

The purpose of our study was to evaluate the feasibility and effects of a cell therapy using human ESC-derived mesodermal cardiogenic cells in our porcine model of chronic overloaded RV dysfunction. ${ }^{10}$ The impact of this treatment on hemodynamic and rhythmic parameters was evaluated throughout the follow-up; the fate of cardiac progenitors and the RV structural remodeling were assessed.

\section{METHODS}

\section{Experimental Design}

Twelve Landrace male piglets were studied in accordance with European Union regulations (Directive 86/609 EEC). This study was approved by the French Ministry of Agriculture (approval No. B92-019-01) and the Committee on Ethics of Animal Experiments
CEEA26 CAPSud. Animals underwent an electrocardiogram (ECG) and hemodynamic evaluation at 3 points in the experiment: baseline, and 4 and 7 months of follow-up. The surgical procedure mimicking repaired TOF was performed after the baseline step. Briefly, an enlargement of the RV outflow tract by a polytetrafluoroethylene patch, excision of 1 pulmonary valve leaflet, and a pulmonary artery banding were performed. ${ }^{10}$ The rhythmic risk was evaluated throughout the cell-therapy period. Histologic analyses were performed on each animal at the end of the procedure.

\section{Cardiac Progenitor Characteristics and Implantation into the RV Myocardium}

Human $\mathrm{MesP}^{+}$(mesoderm posterior 1)/SSEA-1 ${ }^{+}$(stage-specific embryonic antigen-1; CD15) cardiac progenitor cells derived from the HUES-24 (human embryonic stem) cell line were used. Briefly, HUES-24 cells were treated with $100-\mathrm{ng} / \mathrm{ml}$ Wnt 3 a for 24 hours and then with 10-ng/ml BMP2 for 3 days; cells were sorted with a biotin anti-CD15 antibody (Exbio, CliniSciences, Nanterre, France) and antibiotin conjugated beads (Miltenyi Biotec, Paris, France). RNAs extracted from both $\mathrm{CD} 15^{+}$and $\mathrm{CD} 15^{-}$cells were submitted to reverse transcriptase. Complementary DNAs were run in a real-time polymerase chain reaction, as described elsewhere. ${ }^{13}$ Cell characteristics are presented in Figure 1. The selection excludes undifferentiated or early neural stem cells, and no teratoma or proliferative cell foci formation was detected on explanted heart, lung, or liver using scanner multislices imaging (Somatom Definition Flash, Siemens Healthcare, St. Denis, France).

Cell transplantation was performed 4 months after surgery through a right thoracotomy approach. Animals received either medium containing mesodermal cardiogenic cells (treated group: $\mathrm{n}=6$ ) or vehicle alone (sham group: $\mathrm{n}=6)$. The total bolus $\left(10^{7}\right.$ cells) was injected into the RV free wall at 20 separate injection sites; 20 other injections were made in a high-density (HD) area of $1 \mathrm{~cm}^{2}$ identified by nonabsorbable sutures, using a 28 -gauge needle ( $3 \mathrm{~mm}$ deep, $25 \mu \mathrm{l} / \mathrm{site}$ ) connected to a mesotherapy pistol (DHN-2, Techdent, Sallanches, France). Hydrocortisone $(1 \mathrm{mg} / \mathrm{kg}$ ) was injected intravenously before closing, to reduce inflammation. All animals were immunosuppressed by tacrolimus by mouth $(0.3 \mathrm{mg} / \mathrm{kg} /$ day, plasmatic level: see Table 1$)$.

\section{ECG and Rhythm Study}

A 12-lead surface ECG was recorded, and QRS duration was analyzed. ${ }^{10}$ An insertable recorder (Reveal, Medtronic France SAS, Boulogne-Billancourt, France) was implanted subcutaneously under the left scapula at the time of cell implantation, to record the heart's rhythm until the end of follow-up. This cardiac monitor was programmed to record tachycardia $>200$ /minutes, during at least 6 complexes. As a last step, a stored ECG was collected by percutaneous interrogation, and a programmed ventricular stimulation (PVS) was carried out with a quadripolar catheter inserted into the RV apex through the femoral vein.

Standard clinical PVS protocols were employed, including application of single, double, and triple extrastimuli of increasing prematurity until reaching the RV refractory period, after a sequence of 8 conditioning stimuli. The heart was then challenged 3 times with a sequence of 8 , followed by a single extrastimulus at compulsory rhythms of 100, 120, and 150/minutes. If no ventricular tachycardia was induced, this procedure was repeated to apply 3 challenges with double, and if necessary triple, extrastimuli. The PVS was considered positive if these challenges produced sustained ventricular tachycardia $(>30 \mathrm{~s})$ or ventricular fibrillation.

\section{Hemodynamic Study}

Quantification of RV overload and contractile performance of RV myocardium were assessed by the conductance catheter technique. Briefly, the conductance catheter was inserted in the right ventricle through the 


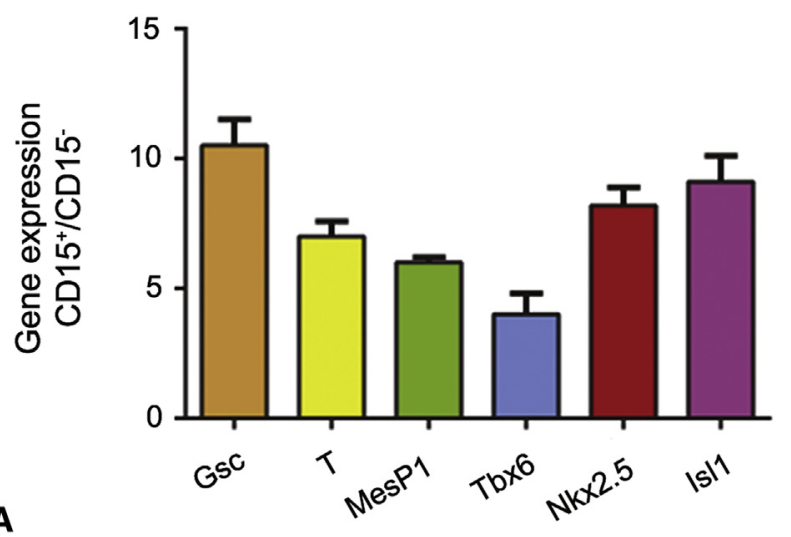

B
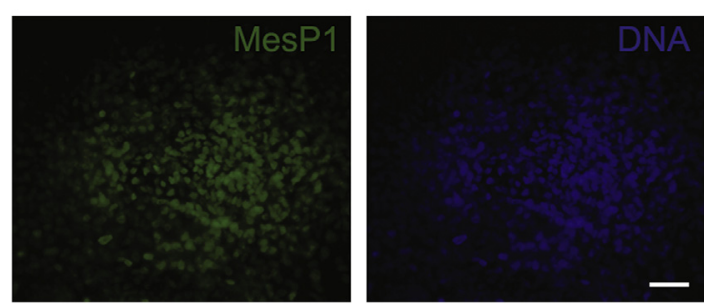

FIGURE 1. Characteristics of Wnt3a/BMP2 treated cells sorted with an anti-CD15 antibody. Data are expressed as the ratio of gene expression in $\mathrm{CD} 15^{+}$cells versus the $\mathrm{CD} 15^{-}$, after normalization with GAPDH for Goosecoid (Gsc), brachyury (T) MesP1, Tbx6, Nkx2.5, and Is11 (A). Staining of $\mathrm{CD}^{+} 5^{+}$cells plated for 12 hours on fibronectin-coated coverslips with an anti-MesP1 antibody (Bioss Inc, Woburn, Mass) and Dapi (DNA, nuclei) (B); bar $=50 \mu \mathrm{m}$. DNA, Desoxuribose nucleic acid.

femoral vein, under fluoroscopic guidance; a balloon was inflated in the caudal vena cava to obtain inflow occlusion. ${ }^{10}$ The effective stroke volume was calculated as the difference between the total stroke volume and the measured volume of the pulmonary regurgitation. The effective ejection fraction was calculated as the ratio between effective stroke volume and end-diastolic volume. The RV contractile status was examined using the end-systolic pressure-volume relationship, slopes of which $\left(\mathrm{E}_{\max }\right)$ were computed during vena cava occlusion. The systolic pressure-volume area, correlated linearly with ventricular oxygen consumption/beat, was calculated as the area enclosed by the end-systolic and end-diastolic pressure-volume relationships and the systolic pressure-volume trajectory; it represents the total mechanical energy consisting of both external work (or stroke work) and mechanical potential energy. ${ }^{15}$

\section{Detection of Engrafted Cells in the Host Myocardium}

Indirect immunofluorescence labeling was performed on free wall and HD-area frozen sections using anti-human nuclei antibodies (EMD Millipore, Molsheim, France) to detect progenitor cells. Genomic DNA was prepared from RV free wall and HD-area pieces using the DNeasy Blood \& Tissue Kit (Qiagen, Venlo, Netherlands). Samples were submitted to polymerase chain reaction analysis, to quantify the presence of human cells using amplification of human ALU sequences using TaqMan (Life Technologies SAS, Saint Aubin, France). ${ }^{16}$ The negative control DNA was isolated from sham RV pieces. The positive control DNA was isolated from atrial human samples (Kremlin Bicêtre Ethics Committee, protocol 04-26).

\section{Histologic Analysis and Immunohistochemistry}

After heart explantation, a gross morphologic examination was performed, and the RV area was estimated by planimetric measurements.
RV free wall and HD-area tissue samples were fixed in $4 \%$ formalin and embedded in paraffin. Sections (3- $\mu \mathrm{m}$ thick) were stained with Picrosirius Red F3BA, hematein/eosin, or an anti-von Willebrand factor (1/600, Dako France SAS, Les Ulis, France). Pictures were recorded at 20X, and analyses were conducted by 2 independent blinded investigators. Collagen quantification was performed on 6 sections (20 fields/section) per animal, expressed as a percentage of total tissue, and its distribution (interstitial and peri-myocyte) was analyzed. Myocyte diameters were determined by measuring the short axis of 30 cells/field (20 fields/animal). All measurements were performed with ImageJ software. Anatomic pathologists determined the tissue inflammatory status and evaluated the neoangiogenesis after von Willebrand-factor immunostaining. To assess the remodeling evolution of our animal model, we included in our data set new analyses of samples issued from animals described in our previous study, ${ }^{10}$ named nonoperated 4 months and operated sham 4 months (Figures E1 and E2).

\section{Statistical Analysis}

Analyses were performed with statistical softwares GraphPad (Prism 5, GraphPad Software, http://www.graphpad.com) and R (version 3.1.0; R Foundation, www.r-project.org). Data were tested for normality and expressed as mean $\pm \mathrm{SD}$, or median and range after the result of the Shapiro-Wilk test. The 2 groups (sham and treated) were compared by 1-way analysis of variance for repeated measures (baseline, 4 months, 7 months) including post hoc analysis by Fisher protected least significant difference test when appropriate, or by nonparametric test for repeated measures (Friedman test with replication and Wilcoxon matched-pair signed-rank test) within groups, and Mann-Whitney $U$ test between groups. For histologic data, a Mann-Whitney $U$ test or a Kruskall-Wallis analysis of variance (Dunn's post hoc analysis) were applied. A $P$ value $<.05$ (2-sided) was considered significant.

\section{RESULTS}

\section{Reproducibility of the Experimental Model and Time Evolution of the RV Dysfunction}

Clinical, electric, and hemodynamic characteristics of the animal population described in this study were not significantly different from the previously described population $^{10}$ at 4 months postoperative, confirming the reproducibility of our experimental model. No significant difference was established between the groups at baseline, 4 , or 7 months.

At 7 months postoperative, sham animals presented no complications, gained weight, and showed no clinical signs of heart failure. Heart rate was stable from 4 to 7 months. On ECG, the QRS duration continuously increased indicating the progression of the RV dysfunction. Barometric overload was maintained from 4 to 7 months at a similar level (Table 1): RV end-systolic pressure remained stable at the last follow-up as well as the peak pressure, which was at $50 \%$ of systemic pressure. In contrast, end-systolic and end-diastolic volumes continued to progress. Functional parameters such as RV end-diastolic pressure, central venous pressure, effective ejection fraction, and cardiac index remained stable (Figure 2, $A$ ). Regarding the myocardial contractility, $\mathrm{E}_{\max }$ values showed a slight but not significant decrease at the last step (Figure 2, $B)$; in parallel, energetic parameters including stroke work and pressure-volume area did not change (Figure 2, C). 
TABLE 1. Population, ECG, and intracardiac pressures and volumes in sham and treated groups at each step of experimentation

\begin{tabular}{|c|c|c|c|c|c|c|}
\hline \multirow[b]{3}{*}{ Group } & \multirow{2}{*}{\multicolumn{2}{|c|}{ Baseline }} & \multicolumn{4}{|c|}{ Follow-up } \\
\hline & & & \multicolumn{2}{|c|}{ At 4 months } & \multicolumn{2}{|c|}{ At 7 months } \\
\hline & Sham $n=6$ & Treated $n=6$ & Sham $n=6$ & Treated $n=6$ & Sham $n=6$ & Treated $\mathbf{n}=6$ \\
\hline \multicolumn{7}{|l|}{ Population characteristics } \\
\hline Age (d) & $69.3 \pm 11.8$ & $75.0 \pm 7.9$ & $201.2 \pm 7.1 *$ & $194.8 \pm 8.1 *$ & $303.7 \pm 16.3^{*}, \dagger$ & $289.2 \pm 12.3^{*}$ \\
\hline Weight $(\mathrm{kg})$ & $21.0 \pm 3.6$ & $21.0 \pm 1.5$ & $55.9 \pm 8.0^{*}$ & $58.9 \pm 6.2 *$ & $73.1 \pm 8.1^{*}, \dagger$ & $71.5 \pm 11.9^{*}$ \\
\hline Body length $(\mathrm{cm})$ & $67.0 \pm 4.9$ & $65.5 \pm 4.6$ & $92.5 \pm 4.0^{*}$ & $92.2 \pm 4.9^{*}$ & $102.3 \pm 4.3^{*}, \dagger$ & $103.5 \pm 10.3^{*}$ \\
\hline Body surface area $\left(\mathrm{m}^{2}\right)$ & $0.62 \pm 0.08$ & $0.61 \pm 0.04$ & $1.20 \pm 0.11 *$ & $1.22 \pm 0.09^{*}$ & $1.44 \pm 0.11^{*}, \dagger$ & $1.43 \pm 0.19^{*}, \dagger$ \\
\hline Tacrolimus plasmatic level (ng/ml) & & & $6.0 \pm 1.6$ & $5.9 \pm 3.2$ & $5.7 \pm 3.8$ & $6.0 \pm 3.3$ \\
\hline \multicolumn{7}{|l|}{ ECG } \\
\hline Heart rate (beats/min) & $116 \pm 4$ & $118 \pm 14$ & $91 \pm 18^{*}$ & $97 \pm 11^{*}$ & $84 \pm 20^{*}$ & $84 \pm 11^{*}$ \\
\hline QRS duration (ms) & $59.7 \pm 7.5$ & $59.7 \pm 6.9$ & $72.3 \pm 3.2 *$ & $71.0 \pm 9.9^{*}$ & $85.2 \pm 9.0^{*}, \dagger$ & $82.0 \pm 7.5^{*}, \dagger$ \\
\hline \multicolumn{7}{|l|}{ Intracardiac pressures } \\
\hline Mean aortic blood pressure $(\mathrm{mm} \mathrm{Hg})$ & $58 \pm 9$ & $66 \pm 9$ & $85 \pm 17^{*}$ & $85 \pm 11^{*}$ & $80 \pm 11^{*}, \dagger$ & $74 \pm 8^{*}, \dagger$ \\
\hline Systolic aortic blood pressure $(\mathrm{mm} \mathrm{Hg})$ & $77 \pm 12$ & $85 \pm 10$ & $103 \pm 18^{*}$ & $104 \pm 15^{*}$ & $100 \pm 11^{*}, \dagger$ & $90 \pm 9^{*}, \dagger$ \\
\hline Central venous pressure $(\mathrm{mm} \mathrm{Hg})$ & $1.3 \pm 1.0$ & $1.5 \pm 0.8$ & $4.8 \pm 2.0^{*}$ & $4.7 \pm 1.9^{*}$ & $5.3 \pm 3.0^{*}$ & $4.8 \pm 2.1^{*}$ \\
\hline \multicolumn{7}{|l|}{$\mathrm{RV}$ pressure $(\mathrm{mm} \mathrm{Hg})$} \\
\hline Peak & $20.3 \pm 5.3$ & $22.3 \pm 1.6$ & $50.5 \pm 27.2^{*}$ & $59.2 \pm 14.1^{*}$ & $44.4 \pm 13.9^{*}$ & $56.8 \pm 11.7^{*}$ \\
\hline End-systolic & $11.3 \pm 3.7$ & $13.2 \pm 1.2$ & $42.5 \pm 25.8^{*}$ & $49.2 \pm 9.3^{*}$ & $37.0 \pm 14.6^{*}$ & $50.8 \pm 12.6^{*}$ \\
\hline End-diastolic & $1.5 \pm 1.5$ & $1.7 \pm 0.8$ & $5 \pm 2.9^{*}$ & $5.0 \pm 3.2^{*}$ & $6.5 \pm 3.7^{*}$ & $5 \pm 2.5^{*}$ \\
\hline Ratio systolic pressure RV/Aorta (\%) & $27 \pm 8$ & $27 \pm 5$ & $47 \pm 17^{*}$ & $57 \pm 10^{*}$ & $45 \pm 12^{*}$ & $64 \pm 15^{*}$ \\
\hline \multicolumn{7}{|l|}{ Intracardiac volumes } \\
\hline End-diastolic volume (ml) & $91 \pm 26$ & $85 \pm 15$ & $166 \pm 46^{*}$ & $148 \pm 24^{*}$ & $192 \pm 55^{*}, \dagger$ & $208 \pm 59^{*}, \dagger$ \\
\hline End-systolic volume (ml) & $45 \pm 19$ & $39 \pm 9$ & $80 \pm 39$ & $67 \pm 20$ & $83 \pm 37^{*}$ & $103 \pm 36^{*}$ \\
\hline Stroke volume (ml) & $44 \pm 10$ & $42 \pm 5$ & $69 \pm 5^{*}$ & $71 \pm 1^{*}$ & $95 \pm 25^{*}$ & $87 \pm 20^{*}$ \\
\hline Fraction of regurgitation $(\%)$ & & & $22 \pm 9$ & $18 \pm 3$ & $15 \pm 8$ & $18 \pm 3$ \\
\hline
\end{tabular}

$E C G$, Electrocardiogram; $R V$, right ventricle. ${ }^{*} P<.05$ versus corresponding group at baseline. $\dagger P<.05$, corresponding group at 7 months versus 4 months.

\section{Cell Therapy: Clinical Tolerance, Hemodynamic Effects, and Rhythmic Impact}

Transmyocardial injections were performed after a similar length of time after the operation in each group $(120 \pm 9$ days in treated, $132 \pm 5$ days in sham). Only transient arrhythmias were observed at the time of needle penetration, and they were fully resolved after injections. No death occurred as a result of the cell injection procedure, or during the follow-up, and no severe adverse effects occurred. Immunosuppression therapy was well tolerated. During the postinjection period, animals gained weight (Table 1) and showed no clinical signs of either heart failure or immune rejection. No difference between treated and sham groups was observed in the RV dysfunction evolution (Table 1). Functional characteristics, contractility parameters, and energetics similarly evolved after either placebo or cell injections (Figure 2).

On ECG, the QRS duration continuously increased, in similar fashion in both the sham and treated groups (Table 1). Despite this risk factor of arrhythmia, all treated animals showed normal long-duration Holter recordings, and no ventricular arrhythmia could be induced by PVS. In contrast, sinus pauses $>2$ seconds were detected on long-duration Holter in 2 sham animals. In one of them, a nonsustained ventricular tachycardia was induced twice after a single extrastimulus at a compulsory rhythm of 120/min and a ventricular fibrillation had occurred after PVS. In the other animal, the PVS led to a transitory ST depression that appeared after a sequence of 8 , followed by the single extrastimulus at a compulsory rhythm of $150 /$ min, suggesting an alteration of the myocardial reserve. This arrhythmic susceptibility supports the evolution capacities of our model in accordance with clinical findings.

\section{Fate of Injected Human Cells and Their Effect on RV Tissue Remodeling}

All animals were euthanized about 3 months after injections (94 \pm 12 days in treated, $103 \pm 11$ days in sham). Human cardiogenic mesodermal cells or cardiac cells have been sought in the RV free wall and HD area using 2 different techniques. At the cellular level, immunolabelings against human nuclear antigen did not reveal the presence of human cells. Similarly, at the DNA level, polymerase chain reaction analyses of treated animal samples did not establish the presence of human ALU sequences, thus indicating with a more sensitive approach, the lack of human cell survival at 3 months (data not shown).

Regarding the histologic analysis, human cell injections did not modify either RV area $\left(115.1 \pm 17.3 \mathrm{~cm}^{2}\right.$ in treated, $117.6 \pm 7.9 \mathrm{~cm}^{2}$ in sham) or myocyte diameters (23.2 $\pm 1.2 \mu \mathrm{m}$ in treated, $22.2 \pm 2.4 \mu \mathrm{m}$ in sham). No inflammatory infiltrates were observed in either group, in 

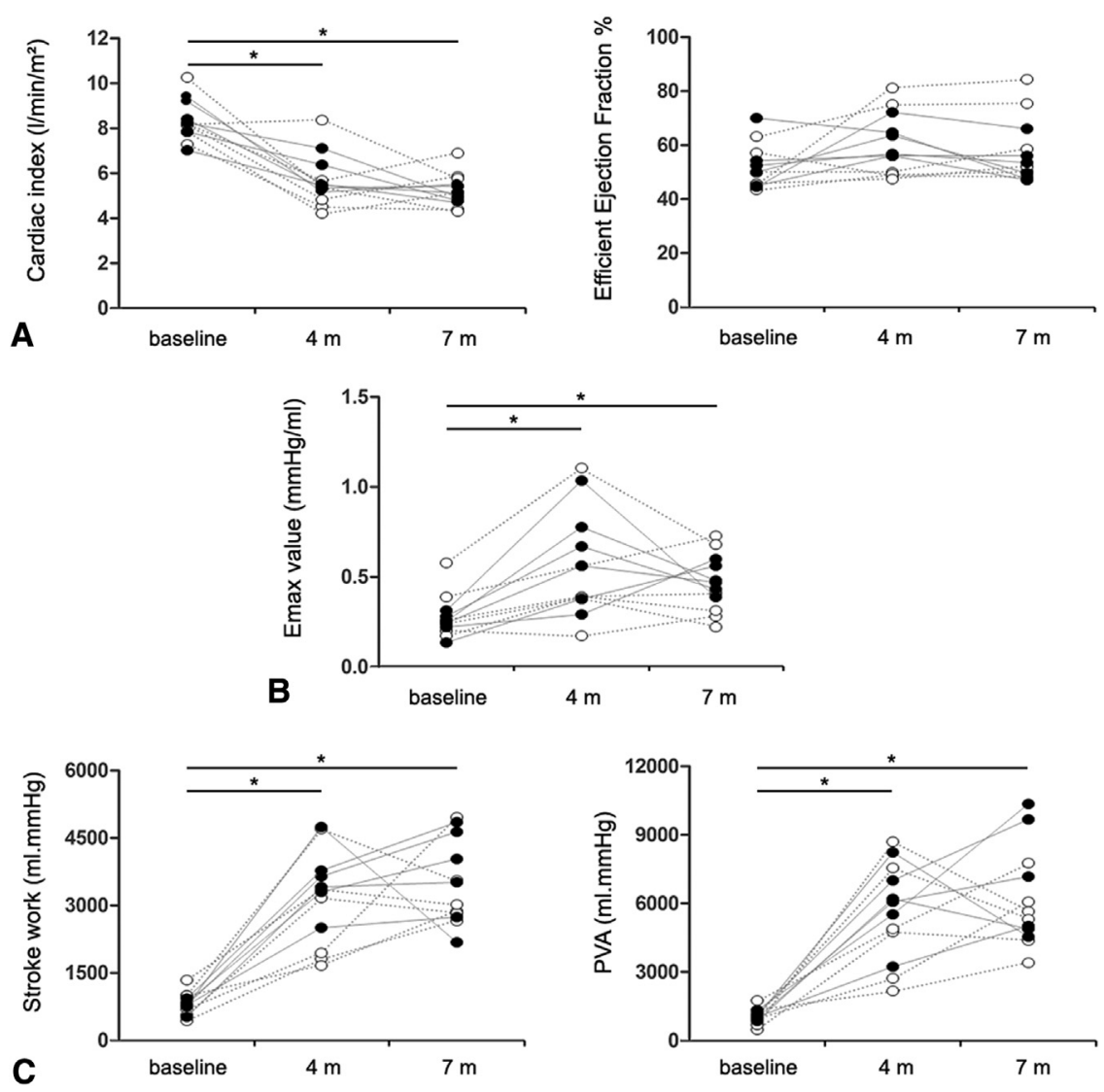

FIGURE 2. Hemodynamic parameters issued from pressure-volume loop measurements. A, RV functional parameters: cardiac index and effective ejection fraction; B, contractility index: $\mathrm{E}_{\max }$ value; and $\mathrm{C}$, energetics parameters: stroke work and pressure volume area. Values at baseline, 4 months $(4 \mathrm{~m}), 7 \mathrm{months}$ $(7 \mathrm{~m})$, for treated (black, $\mathrm{n}=6$ ) and sham (white, $\mathrm{n}=6$ ) animals, are plotted. $* P<.05 ; P V A$, Pressure volume area.

either the free wall or HD area. The vascular density determined by von Willebrand-factor immunolabeling was equivalent in both groups in either the free wall or HD area (data not shown), indicating the absence of neoangiogenesis due to human cells. Regarding fibrosis, human cells induced an important decrease compared with sham animals $(10.53 \% \pm 2.53 \%$ vs $17.72 \% \pm 2.01 \%$; $P<.01$ ) (Figure 3, $A$ and $D$ ). This diminution was mainly due to the drop of the peri-myocyte fibrosis, whereas the interstitial fibrosis was similar (Figure 3, $B-D$ ).

\section{DISCUSSION}

Herein, we describe the first attempt of cell therapy using cardiogenic mesodermal cells issued from human ESCs in a porcine model of overloaded RV dysfunction that mimics congenital diseases. Feasibility, good tolerance, and a beneficial impact on arrhythmic susceptibility and RV fibrosis were demonstrated.

Our model of RV dysfunction on a large animal ${ }^{10}$ is reproducible and mimics, by its evolution, alterations observed in patients with a repaired TOF before a decompensated RV failure. ${ }^{17}$ Indeed, despite an increasing dilation, the porcine $\mathrm{RV}$ adaptive response is maintained in association with depolarization anomalies, translating the alteration of the RV function at an early stage of the disease. These functional observations are associated with a structural remodeling evolution.

When new analyses of samples issued from animals described in our previous study ${ }^{10}$ are included, the RV area seems to be significantly enlarged under combined overload (Figure E1, A). This enlargement is associated with a marked increase of the cardiac myocyte diameter (Figure E1, B). Similarly, fibrosis of the overloaded RV is greater, compared with normal right ventricle (Figure E2). This increase involves only the peri-myocyte fibrosis; the interstitial fibrosis remains stable. These anomalies reproduce the pathology before the depletion of the compensatory mechanisms ${ }^{14,18}$ leading to the first symptoms in patients and alteration of the ejection fraction. ${ }^{19}$

One safety concern in cell therapy is the risk of arrhythmia. Generally, this risk is attributable to not only cells but also the delivery mode and underlying heart disease. ${ }^{20}$ Engrafted cells might encounter significant difficulties in forming electromechanical junctions with the host myocardium, thus becoming an arrhythmogenic 

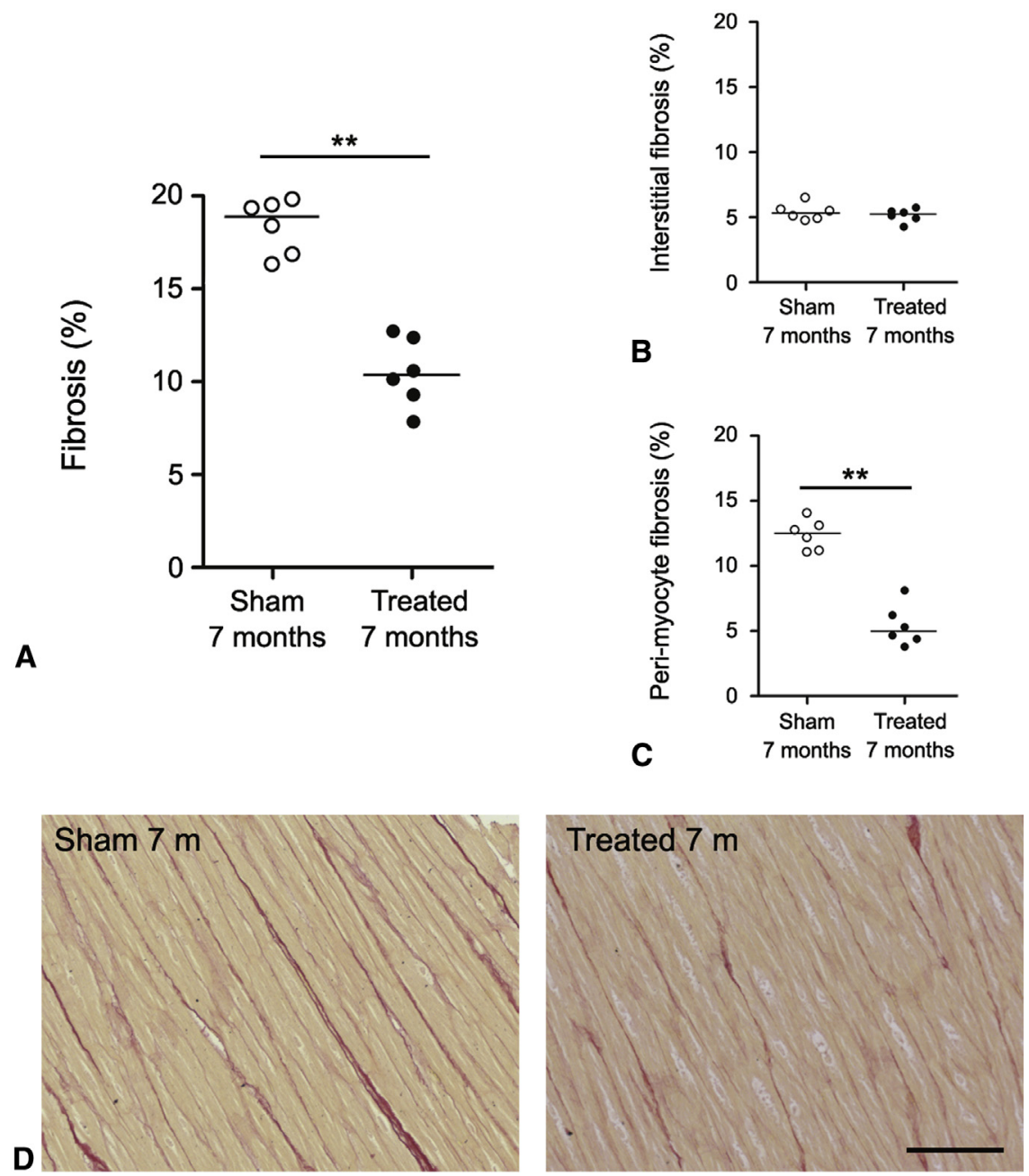

FIGURE 3. Total fibrosis (A) and its distribution in interstitial (B) and peri-myocyte (C) localization after cell therapy. Values at 7 months for treated (black, $\mathrm{n}=6$ ) and sham (white, $\mathrm{n}=6$ ) animals are plotted with lines indicating median. $\mathrm{D}$, Representative longitudinal tissue sections from sham and treated (7 months) animals after Picrosirius red; bar $=100 \mu \mathrm{m}$. **P<.01.

substrate $^{6,21}$ Additionally, intramyocardial injections could contribute to ventricular arrhythmia because of local tissue injuries, independently of the cell type injected. ${ }^{7,20}$ However, in the 3 studies reporting cell therapy applied to the right ventricle, ${ }^{7-9}$ all used multiple intramyocardial injections, and none described any arrhythmic susceptibility.

In our study, those injections did not lead to immediate sustained arrhythmia. Moreover, as in patients, ${ }^{22}$ our experimental model itself presents risk factors for severe ventricular arrhythmia ${ }^{10}$ : QRS prolongation, RV dilation, and myocyte hypertrophy. Despite these risk factors, which are similar in the 2 groups, only the sham animal group presented, during the postinjection period, an arrhythmic susceptibility detected with 2 different techniques, suggesting that treated animals could be protected against arrhythmia by ESC-issued cardiogenic mesodermal cell injections. Evidential support for this beneficial effect may come from the normalization of the RV fibrosis (Figure E2), as described in other experimental models. ${ }^{23,24}$ However, in our study, this complete fibrosis regression did not lead to a shortening of QRS duration, suggesting that other factors contribute to depolarization anomalies, such as cellular electrophysiology alterations observed on action potentials in our model.

Stem cell-derivative engraftment is now recognized to significantly decrease fibrosis in the heart after ischemic left ventricle injury using mesenchymal ${ }^{25}$ as well as embryonic stem cells. ${ }^{6,13,26}$ Conversely, for mesenchymal stem cells acting in a paracrine fashion on fibrosis, ${ }^{25}$ ESC-derived cardiac progenitors are able to differentiate and repopulate fibrosis areas. ${ }^{6,13,26}$ In our study, the absence of human cardiac progenitors in treated animals suggests that such cells have additional effects, which would explain the RV fibrosis normalization and the protective effect against arrhythmia. Indeed, a paracrine 
effect of $\mathrm{MesP} 1^{+} / \mathrm{SSEA}-1^{+}$-secreting vascular endothelial growth factor-A has been shown in a recent model of limb ischemia. ${ }^{27}$ In addition, these paracrine effects, mediated through vascular endothelial growth factor, may result from a modulation of local inflammation, ${ }^{28}$ and/or, by analogy with mesenchymal stem cells, the secretion of soluble factors acting directly on matrix metalloproteinases and matrix metalloproteinase endogenous inhibitor production by cardiac fibroblasts. ${ }^{25}$

The reason for the lack of grafted $\mathrm{MesP}^{+} / \mathrm{SSEA}-1^{+}$ cardiac progenitors within the myocardium in our study remains unclear, whereas the RV structural remodeling constituted a favorable environment to cell engraftment. ${ }^{10,13}$ Blin and colleagues ${ }^{13}$ indicated successful engraftments of the same cell type at 2 months after transmyocardial injections. ${ }^{13}$ Our results underline the long-term survival failure of such cells. One explanation may be the immune rejection of ESCs. ${ }^{29}$ Herein, the immunosuppressive regimen was efficient, as plasmatic tacrolimus levels revealed therapeutic values as recommended in human after organ transplantation, and as no inflammatory infiltrates were detected during histologic analyses. Another reason could be related to a hypoxic environment of grafted cells. Since RV outflow-tract diseases were not corrected, the RV chronic pressure overload was maintained, leading to a diminished anatomic capillary vascular reserve ${ }^{30}$ that limited the blood supply to engrafted cells and affected cardiac progenitor survival. $^{31}$

In contrast to the results of cell therapies applied to ischemic models, no functional improvement was observed, despite the fibrosis normalization. As RV outlet tract diseases were not corrected, benefits of the fibrosis decrease might not have been sufficient to balance the deleterious effects of combined overload and lead to a detectable functional improvement. Regarding cell therapies applied to the right ventricle, only Davies and colleagues ${ }^{9}$ reported an enhancement of systolic RV function 1 month after injections of human cord-blood stem cells into neonatal pressure-loaded RV myocardium. However, these findings need to be interpreted cautiously, because a significant RV function improvement was observed, though to a lesser degree, without stem cell transplantation, suggesting that the improvement may reflect homeometric adaptation. $^{32}$ Others $^{7,8}$ did not find any RV systolic functional improvement. Overall, these results underline the difficulties and the specificity of the cell therapy treatment necessitated by RV failure, compared with ischemic left ventricular dysfunction.

\section{CONCLUSIONS}

Cell therapy using human $\mathrm{MesP} 1^{+} / \mathrm{SSEA}-1^{+}$cardiogenic mesodermal cells applied to an overloaded right ventricle is feasible in a large animal model, well tolerated, and has beneficial effects on fibrosis and arrhythmic susceptibility. Next objectives are, first, to improve the long-term survival of ESC-derived cardiac progenitors using more-protective delivery modes and prosurvival factors ${ }^{33}$; and second, to promote their migration and differentiation into the RV myocardium.

The authors thank Alain Chapel for ALU sequence analyses; Nicolas Raymond for his excellent histologic work; Dr Dorfmüller and Dr de Montpreville for anatomic-pathology expertise; Dr Stos for his technical assistance; and the Surgical Research Staff: Benoit Decante, Bruno Baudet, Frédéric Seccatore, and Anaelle Le Breton for technical assistance and animal care.

We greatly acknowledge the Surgical Research Laboratory and Microscopy Facility of the Centre Chirurgical Marie Lannelongue and the Bligny Farm.

\section{References}

1. Norozi K, Wessel A, Alpers V, Arnhold JO, Geyer S, Zoege M, et al. Incidence and risk distribution of heart failure in adolescents and adults with congenital heart disease after cardiac surgery. Am J Cardiol. 2006;97: 1238-43.

2. Lopez L, Cohen MS, Anderson RH, Redington AN, Nykanen DG, Penny DJ, et al. Unnatural history of the right ventricle in patients with congenitally malformed hearts. Cardiol Young. 2010;20(Suppl 3):107-12.

3. Vonk-Noordegraaf A, Haddad F, Chin KM, Forfia PR, Kawut SM, Lumens J, et al. Right heart adaptation to pulmonary arterial hypertension: physiology and pathobiology. J Am Coll Cardiol. 2013;62(25 Suppl):D22-33.

4. Voelkel NF, Quaife RA, Leinwand LA, Barst RJ, McGoon MD, Meldrum DR, et al. Right ventricular function and failure: report of a National Heart, Lung, and Blood Institute working group on cellular and molecular mechanisms of right heart failure. Circulation. 2006;114:1883-91.

5. Winter MM, Bouma BJ, Groenink M, Konings TC, Tijssen JG, van Veldhuisen DJ, et al. Latest insights in therapeutic options for systemic right ventricular failure: a comparison with left ventricular failure. Heart. 2009;95: 960-3.

6. Chong JJ, Yang X, Don CW, Minami E, Liu YW, Weyers JJ, et al. Human embryonic-stem-cell-derived cardiomyocytes regenerate non-human primate hearts. Nature. 2014;510:273-7.

7. Borenstein N, Jian Z, Fromont G, Bruneval P, Hekmati M, Behr L, et al. Noncultured cell transplantation in an ovine model of right ventricular preparation. J Thorac Cardiovasc Surg. 2005;129:1119-27.

8. Yerebakan C, Sandica E, Prietz S, Klopsch C, Ugurlucan M, Kaminski A, et al. Autologous umbilical cord blood mononuclear cell transplantation preserves right ventricular function in a novel model of chronic right ventricular volume overload. Cell Transplant. 2009;18:855-68.

9. Davies B, Elwood NJ, Li S, Cullinane F, Edwards GA, Newgreen DF, et al. Human cord blood stem cells enhance neonatal right ventricular function in an ovine model of right ventricular training. Ann Thorac Surg. 2010;89:585-93. e581-4.

10. Lambert V, Capderou A, Le Bret E, Rucker-Martin C, Deroubaix E, Gouadon E, et al. Right ventricular failure secondary to chronic overload in congenital heart disease: an experimental model for therapeutic innovation. J Thorac Cardiovasc Surg. 2010;139:1197-204. e1191.

11. Kozak MF, Redington A, Yoo SJ, Seed M, Greiser A, Grosse-Wortmann L. Diffuse myocardial fibrosis following tetralogy of Fallot repair: a t1 mapping cardiac magnetic resonance study. Pediatr Radiol. 2014;44:403-9.

12. Bolli R, Tang XL, Sanganalmath SK, Rimoldi O, Mosna F, Abdel-Latif A, et al. Intracoronary delivery of autologous cardiac stem cells improves cardiac function in a porcine model of chronic ischemic cardiomyopathy. Circulation. 2013;128:122-31.

13. Blin G, Nury D, Stefanovic S, Neri T, Guillevic O, Brinon B, et al. A purified population of multipotent cardiovascular progenitors derived from primate pluripotent stem cells engrafts in postmyocardial infarcted nonhuman primates. J Clin Invest. 2010;120:1125-39. 
14. Richart ALX, Neri T. Ventricular fibrosis suggested by cardiovascular magnetic resonance in adults with repaired tetralogy of fallot and its relationship to adverse markers of clinical outcome. Circulation. 2006;113:405-13.

15. Takaoka H, Takeuchi M, Odake M, Yokoyama M. Assessment of myocardial oxygen consumption (vo2) and systolic pressure-volume area (pva) in human hearts. Eur Heart J 1992;13 Suppl E:85-90.

16. Francois S, Mouiseddine M, Mathieu N, Semont A, Monti P, Dudoignon N, et al. Human mesenchymal stem cells favour healing of the cutaneous radiation syndrome in a xenogenic transplant model. Ann Hematol. 2007;86:1-8.

17. Haddad F, Doyle R, Murphy DJ, Hunt SA. Right ventricular function in cardiovascular disease, part ii: pathophysiology, clinical importance, and management of right ventricular failure. Circulation. 2008;117:1717-31.

18. Chowdhury UK, Sathia S, Ray R, Singh R, Pradeep KK, Venugopal P. Histopathology of the right ventricular outflow tract and its relationship to clinical outcomes and arrhythmias in patients with tetralogy of Fallot. J Thorac Cardiovasc Surg. 2006;132:270-7.

19. Geva T. Indications and timing of pulmonary valve replacement after tetralogy of Fallot repair. Semin Thorac Cardiovasc Surg Pediatr Card Surg Annu. 2006;11-22.

20. Menasche P. Stem cell therapy for heart failure: Are arrhythmias a real safety concern? Circulation. 2009;119:2735-40.

21. Laflamme MA, Murry CE. Regenerating the heart. Nature Biotechnol. 2005;23: 845-56.

22. Gatzoulis MA, Till JA, Somerville J, Redington AN. Mechanoelectrical interaction in tetralogy of fallot. Qrs prolongation relates to right ventricular size and predicts malignant ventricular arrhythmias and sudden death. Circulation. 1995;92:231-7.

23. Rucker-Martin C, Milliez P, Tan S, Decrouy X, Recouvreur M, Vranckx R, et al. Chronic hemodynamic overload of the atria is an important factor for gap junction remodeling in human and rat hearts. Cardiovasc Res. 2006;72: 69-79.

24. Milliez P, Gomes S, Champ-Rigot L, Callebert J, Samuel JL, Delcayre C. Effects of spironolactone alone and in addition to a beta-blocker on myocardial histological and electrical remodeling in chronic severe failing rat hearts $J$ Cardiovasc Pharmacol. 2012;60:315-21.

25. Mias C, Lairez O, Trouche E, Roncalli J, Calise D, Seguelas MH, et al Mesenchymal stem cells promote matrix metalloproteinase secretion by cardiac fibroblasts and reduce cardiac ventricular fibrosis after myocardial infarction. Stem Cells. 2009;27:2734-43.

26. Puymirat E, Geha R, Tomescot A, Bellamy V, Larghero J, Trinquart L, et al. Can mesenchymal stem cells induce tolerance to cotransplanted human embryonic stem cells? Mol Ther. 2009;17:176-82.

27. Richart ALX, Néri T, Howangyin K, Guérin C, Ngkelo A, Bakker W, et al Microrna-21 coordinates human multipotent cardiovascular progenitors: therapeutic potential and post-ischemic revascularization. Stem Cells. 2014;32: 2908-22.

28. Crisostomo PR, Abarbanell AM, Wang M, Lahm T, Wang Y, Meldrum DR. Embryonic stem cells attenuate myocardial dysfunction and inflammation after surgical global ischemia via paracrine actions. Am J Physiol Heart Circ Physiol. 2008;295:H1726-35

29. Calderon D, Planat-Benard V, Bellamy V, Vanneaux V, Kuhn C, Peyrard S et al. Immune response to human embryonic stem cell-derived cardiac progenitors and adipose-derived stromal cells. J Cell Mol Med. 2012;16: 1544-52.

30. Marino TA, Kent RL, Uboh CE, Fernandez E, Thompson EW, Cooper GT Structural analysis of pressure versus volume overload hypertrophy of cat right ventricle. Am J Physiol. 1985;249(2 Pt 2):H371-9.

31. Wollert KC, Drexler H. Clinical applications of stem cells for the heart. Circ Res 2005;96:151-63.

32. de Vroomen M, Cardozo RH, Steendijk P, van Bel F, Baan J. Improved contractile performance of right ventricle in response to increased rv afterload in newborn lamb. Am J Physiol Heart Circ Physiol. 2000;278:H100-5.

33. Laflamme MA, Chen KY, Naumova AV, Muskheli V, Fugate JA, Dupras SK, et al Cardiomyocytes derived from human embryonic stem cells in pro-survival factors enhance function of infarcted rat hearts. Nat Biotechnol. 2007;25: 1015-24.

\section{EDITORIAL COMMENTARY}

\section{Myocardial regeneration for chronic heart failure: Not as easy as it sounds}

Richard A. Hopkins, MD

See related article on pages 708-15.

From the Cardiac Regenerative Surgery Research Laboratories, Ward Family Heart Center, Kansas City, Mo.

Disclosures: Author has nothing to disclose with regard to commercial support.

Received for publication Dec 5, 2014; accepted for publication Dec 6, 2014; available ahead of print Jan 23, 2015.

Address for reprints: Richard A. Hopkins, MD, Children's Mercy Kansas City, Cardiac Surgery, Ward Family Heart Center, 2401 Gillham Rd, Kansas City, MO 64108 (E-mail: rahopkins@cmh.edu).

J Thorac Cardiovasc Surg 2015;149:715-7

$0022-5223 / \$ 36.00$

Copyright $(2015$ by The American Association for Thoracic Surgery

http://dx.doi.org/10.1016/j.jtcvs.2014.12.021
Virginie and colleagues ${ }^{1}$ describe the absence of functional benefit from injections of human embryonic stem cell-derived (hESC) cardiac progenitors into chronically volume overloaded piglet right ventricles. Further, the authors report 0 persistence of injected cells in the right ventricle myocardium, no neoangiogenesis, no myocardial regeneration, and quantitatively no effect on interstitial myocardial fibrosis. They did report a statistically insignificant reduction in arrhythmogenicity as well as a roughly $50 \%$ decrease in perimyocyte fibrosis in the cell-treated animals compared with the sham injected hearts. The significance of this is unclear, because both chronic ventricular overloading and ischemic necrosis result in interstitial fibrosis leading to dysfunction. It is yet another failed animal 

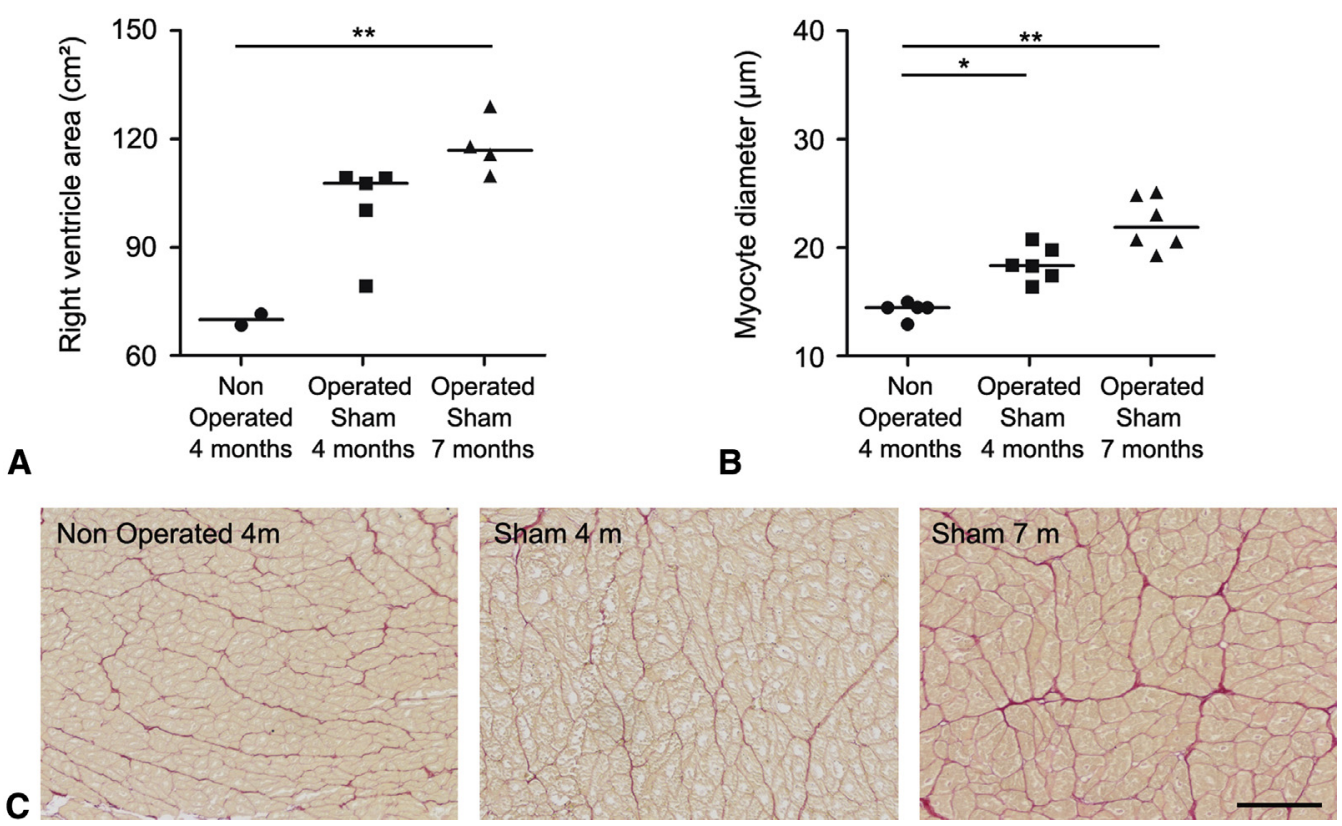

FIGURE E1. Evolution of the right ventricle area (A) and cardiac myocyte diameters (B) during right ventricle chronic overload. Representative transversal tissue sections from nonoperated and operated sham (4 months), and operated sham (7 months) animals after Picrosirius red; bar $=100 \mu \mathrm{m}(\mathrm{C})$. $* P<.05, * * P<.01$.
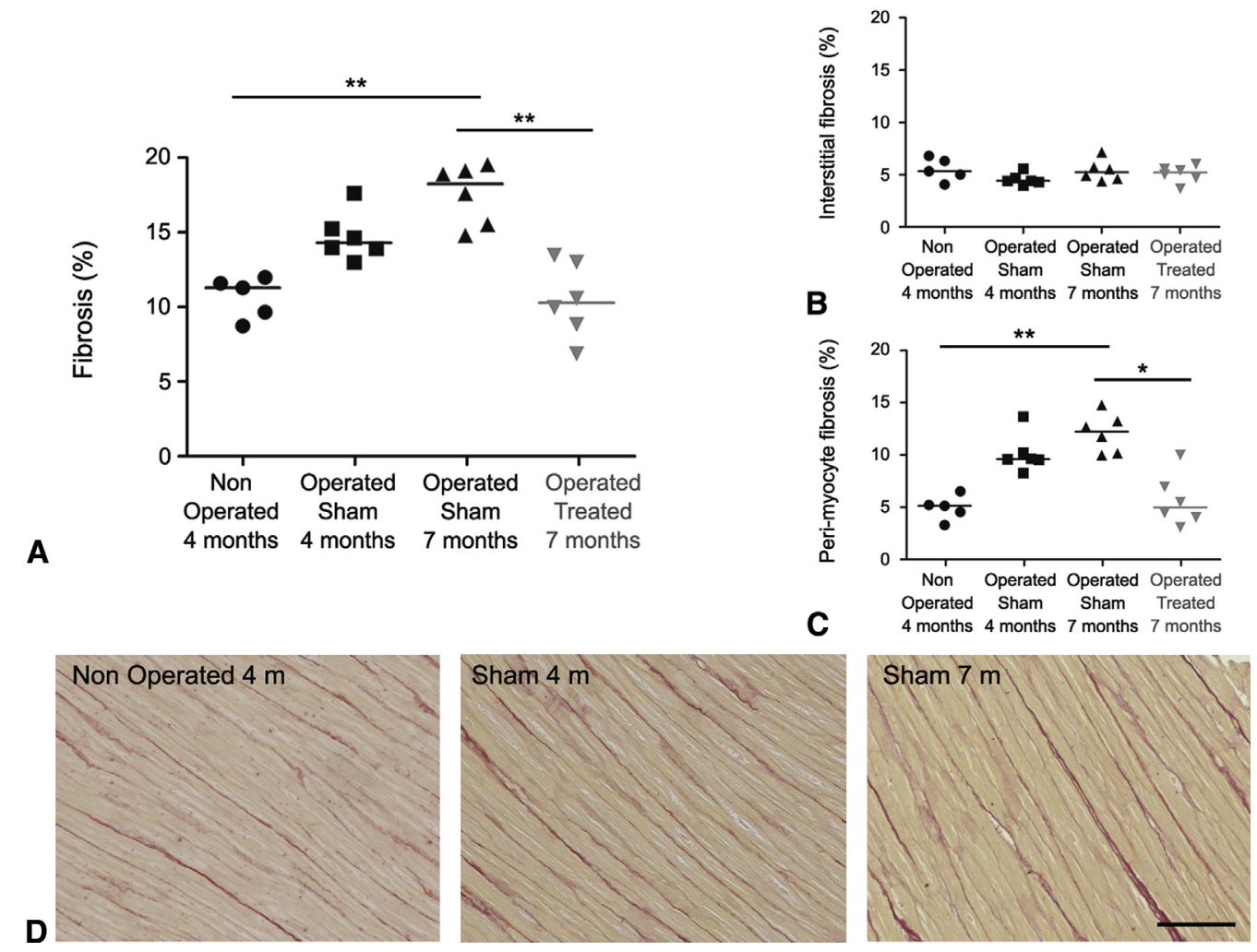

FIGURE E2. Evolution of the total fibrosis (A) and its distribution in interstitial (B), and peri-myocyte (C) localization during right ventricle chronic overload and after cell therapy. The 4 months data set shows results of new analyses of samples issued from animals described in our previous study. ${ }^{10}$ Values at 4 months $(4 \mathrm{~m})$ and 7 months $(7 \mathrm{~m})$, for nonoperated and operated sham (black) and treated (gray) animals are plotted with lines indicating median. Fibrosis was significantly reduced in treated animals, back to the control level, assessing its complete regression. D, Representative longitudinal tissue sections from nonoperated and operated sham (4 months), and operated sham (7 months) animals after Picrosirius red; bar $=100 \mu \mathrm{m}$. Kruskall-Wallis analysis of variance (Dunn's post hoc test); ${ }^{*} P<.05$, ${ }^{* *} P<.01$. 